\title{
The Analysis of the Factors Affecting China's Export of Cultural Products to Countries along the Belt and Road
}

\author{
Pei-Zhi Wang ${ }^{1, \text { a }}$, Shu-Yue Zhang ${ }^{2, \text { b }}$, Li-Ping Sun ${ }^{3, \text { c }}$ \\ 1, 2, 3 Shandong University of Finance and Economics \\ School of International Economics and Trade \\ Jinan, China \\ awpzmail@126.com, bsy1994m@163.com, ${ }^{\mathrm{c}} 1550309661 @ \mathrm{qq} . c 0 m$
}

\begin{abstract}
With the continuous development of China's cultural industry, the export of cultural products will become the focus of China's foreign trade in the future, and the deepening of economic and trade cooperation between China and the countries along the "Belt and Road" will make these countries gradually become the growth point of China's export of cultural products. Based on the panel data of China and the countries along the Belt and Road from 2009 to 2015 , this paper uses fixed effect model to analyzes the factors affecting China's export of cultural products to countries along the Belt and Road. The results show that China's GDP scale, the GDP scale of partner countries, the economic freedom of partner countries, the degree of education in partner countries and the degree of communication with the outside world have a significant positive impact on China's Export of Cultural Products to Countries along the Belt and Road. However, the results also show that the multilateral resistance factor, the geographical and cultural distance between the two countries have a significant negative impact on China's export of cultural products to countries along the Belt and Road.
\end{abstract}

Keywords-The "Belt and Road" Initiative; Cultural products; Cultural distance; Gravity model

\section{INTRODUCTION}

In the 19th National Congress of the Communist Party of China, General Secretary Xi proposed a basic strategy of strengthening cultural self-confidence and promoting the prosperity of socialist culture. The report clearly pointed out that to promote the development of cultural industries, so that the export of cultural products will become the focus of China's foreign trade development in the coming period. The "Belt and Road" Initiative is a new type of opening-up strategy for China to actively adapt to the new changes in the international economic and trade pattern, promote the transformation and upgrading of the domestic industrial structure, achieve sustained and rapid economic development in countries along the Belt and Road, and commit to strengthen trade with Asian, European and African countries, two-way investment, industrial transfer and other economic and trade cooperation. As China's economic and trade cooperation with the countries along the "Belt and Road" continues to deepen, these countries will gradually become the growth point of Chinese cultural products exports.
In recent years, the trade volume of cultural products between China and the "Belt and Road" countries have been increasing. The total amount of cultural products exported by China to the "Belt and Road" countries has shown a rapid growth trend in recent years, from 2.407 billion U.S. dollars in 2009 to 4.097 billion in 2015 , which increased by $70.2 \%$. What factors have affected China's exports of cultural products along the "Belt and Road" and how to further promote trade in cultural products between China and these countries? This article will explore the above issues in order to provide relevant policy advice to governments and enterprises.

\section{LITERATURE REVIEW}

In the past ten years, the rapid development of global cultural products trade has received increasing attention and support from governments. It has attracted many scholars from all fields in the world to study the factors affecting the trade of cultural products and the degree of their influence. In the literature, domestic and foreign scholars have discussed the relationship between distance and trade based on different angles. Among them, cultural distance is considered to be an important factor which affects cultural trade. Many scholars have made empirical analysis from language differences (Liu Yang et al., 2013), religious beliefs (Guo R, 2007) [1], ethnic relations (Montalvo et al., 2005) [2]. In addition, some scholars study various influencing factors of cultural product trade. Yu Sasha (2013) empirically tested the impact of economic scale, human environment, per capita income, Internet development, and historical language environment on the trade of cultural products in the publishing industry from 2001 to 2011; Xu Helian et al. (2014) started with three core cultural products, such as handicrafts, publications and audio-visual products, and analyzed the impact of cultural differences on China's core cultural products trade; Shao Jun et al. (2013) mainly studied the impact of the level of broadband infrastructure on the export of cultural products, and believed that good broadband infrastructure in exporting countries could promote the growth of cultural products exports.

In fact, the factors affecting cultural trade are multi-faceted. Therefore, this paper combines cultural, institutional, geographical, economic and other factors to comprehensively 
consider and study the factors influencing the export of cultural products of the "Belt and Road" countries. Secondly, most of the literatures use dummy variables to measure the resistance factors of multilateral trade. This paper selects the number of countries that have signed free trade zones and regional trade agreements between importing countries and non-i countries as the proxy variables of the multilateral resistance factors of importing countries under the condition of bilateral trade cost.

\section{DATA SELECTION AND MODEL ESTABLISHMENT}

\section{A. Data selection and source}

\section{1) Dependent variable}

China's exports scale of cultural products to countries along the Belt and Road (lnEcp): Bilateral cultural product trade data comes from the UNCTAD Creative Economy Database, which provides relevant data for 2002-2015. Considering that the "Belt and Road" Initiative is short-lived and in order to eliminate the impact of the 2008 financial crisis on international trade, this paper will set the inspection period to 2009-2015.

\section{2) Independent variable}

The scale of the exporting country's economy (lnGDPi): After the rapid economic development in recent years, China has accumulated a large economic scale and its commodities supply capacity has increased. The larger the scale of China's economy, the greater the number and variety of its commodities, and the larger the scale of its exports. This paper selects the exporting country's GDP (2010 constant price US dollar) as the proxy variable of China's economic scale, and takes the logarithm. The data source is the World Bank database.

The scale of the partner country's economy (lnGDPj): The demand for products in a country is directly proportional to the scale of the country's economy. In the case of relatively unchanged domestic supply, the larger the scale of the partner country's economy, the more the quantity and variety of its exports to China, the greater the trade volume between the two countries. (Jaimovich;2012) [3]. This paper takes the trading partner's GDP (2010 constant price US dollar) as the proxy variable of the partner country's economic scale and takes the logarithm. The data source is the World Bank database.

Geographical distance (lnDIS): Geographical distance is an important factor affecting trade costs. This paper uses the geographic distance between the capital of the exporting country and the capital of the partner country, and multiplies it by the US West Texas Intermediate crude oil price (WTI) to examine the influence of the change in oil price to the transportation cost. The variable takes the logarithm and then joins the equation.

Multi-trade resistance factors (lnFTAdj): The multilateral resistance factors of importing countries will affect the prices of export commodities in exporting countries. Given the bilateral trade costs between the importing country and the i country, the lowering of the multilateral trade resistance of the importing country means that the relative price of the exporting goods of the $\mathrm{i}$ country is increased, thereby reducing the trade level between the importing country and the i country. This paper selects the number of countries that have signed the free trade zone and regional trade agreements between the importing country and the non-i country as the proxy variable of the multilateral resistance factor of the importing country under the conditions of given bilateral trade costs. The more the number of countries signing, the smaller the resistance of the importing country. At the same time, it means that the economic distance between the importing country and the country of $i$ increases. The data was compiled through the WTO trade topic.

Cultural distance (lnCDI): Cultural distance refers to the different degrees of norms and values embodied by people in one country and another. It can be used to distinguish moral values, values and beliefs between two countries. When the cultural distance is small, consumers have higher recognition and acceptance of each other's products, which is conducive to bilateral trade. Based on the rights distance, risk aversion, individualism and collectivism, male and female of Hofstede cultural dimension, which is a four-dimensional measurement indicator [4], this paper uses the Pythagorean theorem to perform weighted synthesis to calculate a comprehensive cultural distance indicator between China and the "Belt and Road" countries. The specific formula is:

$$
C D_{j}=\sum_{i=1}^{4}\left[\left(I_{i j}-I_{i C H}\right)^{2} / V_{i}\right] / 4
$$

Among them, $C D_{j}$ refers to the cultural distance between the host country $j$ and China, $I_{i j}$ refers to the cultural distance of the host country's i dimension, $I_{i C H}$ refers to the cultural distance of the Chinese $\mathrm{i}$ dimension, and $V_{i}$ refers to the variance of the $\mathrm{i}$ dimension cultural distance. Considering that the cultural distance should be changed over time, this paper substitutes the number of Confucius Institutes per square kilometer into the variable, ie the cultural distance* $(1+$ the number of Confucius Institutes per square kilometer).

\section{3) Control variable}

Exporting countries direct investment in partner countries (lnOFDIs): With the expansion of China's economic scale and the promotion of related strategies such as "going out", China's foreign direct investment has increased rapidly in recent years. Foreign direct investment and exports, as the two main ways to enter the target market, have certain mutual substitution. In the context of globalization of resource allocation, foreign direct investment will increase the import demand of the host country to the home country, as well as cultural products. This paper uses China's direct investment stocks in trading partners to measure the impact of OFDI on cultural product exports, then take a logarithm. The data was compiled through the "China Foreign Direct Investment Bulletin".

Economic freedom (lnES): Economic freedom, published by the Wall Street Journal and the American Heritage Foundation, is one of the world's most authoritative indicators of economic freedom. The higher the score on an indicator, the higher the level of government interference with the economy, and the lower the degree of economic freedom. After the indicators are accumulated and averaged, the overall coefficient can be calculated. Countries or regions with more economic freedom will have higher long-term economic growth and prosperity, and are more likely to accept cultural products from other countries.

Trade openness $(\operatorname{lnOPENj})$ : That is, the degree of trade dependence, which represents the importance of a country's foreign trade relative to the national economy, and reflects the 
country's trade policy, the openness of the trade system, and the ease with which trade goods enter the country. Open trade is conducive to reducing the cost of Chinese exports entering the country's market, thereby promoting the export of Chinese cultural products. The data source is the World Bank database.

Enrollment rate of colleges and universities (lnhc) and Internet usage of 100 people (lnict): The level of education and communication with the outside world may broaden the horizon and affect the acceptance of cultural products of exporting countries by the residents of the partner countries. Therefore, the influence of such factors on the export of cultural products should be considered. This article uses the enrollment rate of colleges and universities to indicate the level of education, and uses the Internet usage of 100 people to express the ability to communicate with the outside world. The data source is the World Bank database.

\section{B. Model establishment}

Based on the general form of gravity model of Bergstrand (1985, 1989) [5][6] and Anderson and Wincoop (2003)[7], we take the particularity of cultural products into account. According to the description in Section III.A, we bring variables such as cultural distance into the traditional model. The model is finally established as follows:

$$
\begin{aligned}
& \ln E c p_{i j t}=\ln G D P_{i}+\ln G D P_{j}+\ln D I S+\ln F T A_{d j}+ \\
& \ln C D I+\sum_{n} \theta_{n} C_{j t}^{n}+\delta_{t}+\mu_{t}
\end{aligned}
$$

Among them, $\operatorname{lnEcp}{ }_{i j t}$ refers to China's exports scale of cultural products to countries along the Belt and Road, $\operatorname{lnGDP}_{i}$ is the scale of China's GDP, $\ln G D P_{j}$ is the scale of the partner country's GDP, InDIS is the geographical distance between the two countries, $\operatorname{lnFT} A_{d j}$ is multilateral resistance factor, $\operatorname{lnCDI}$ is the cultural distance between the two countries, $C_{j t}^{n}$ refers to the relevant control variables, including OFDI stock, economic freedom, trade openness, college enrollment rate, Internet usage of 100 people, $\delta_{t}$ refers to the fixed benefit, and $\mu_{t}$ represents the random error term.

It can be seen from the correlation coefficient matrix that the correlation coefficient between other variables is less than 0.7 except that the correlation coefficient of lnGDPj and lnOFDIs (0.7538) is higher than 0.7. In addition, the correlation coefficient between lnhe and lnict is also higher than 0.7 , but these two variables will not appear in the same test model, so there is no collinearity problem. We further investigate the variance expansion factor, which is calculated to have a VIF of 1.55 , which is much less than 10 , and it is determined that there is no serious collinearity between the variables.

Considering the availability and continuity of data, this paper uses the panel data of China and 30 "Belt and Road" countries in 2009-2015 to examine the factors affecting China's export of cultural products to countries along the Belt and Road. Regarding the test method, the panel data test has mixed estimates, fixed effects, and random effects. First, we use the LM test, and the results reject the null hypothesis that the model uses mixed estimates. Second, we performed the Hausman test, and the results rejected the model using random effects. Therefore, we use a fixed effect to test.

\section{EMPIRICAL ANALYSIS}

According to Table 1, lnGDPi is significant at the level of 5\% to $10 \%$ and the coefficient is positive, indicating that China's large economic scale and strong economic strength may increase the influence of Chinese culture, which is more conducive to exporting cultural products to countries along the "Belt and Road". The coefficient of $\operatorname{lnGDPj}$ is positive, but the significance is poor, indicating that although the market size of partner countries has a positive impact on the export of cultural products along the "Belt and Road" countries, the impact is not strong. This may be due to the fact that cultural product exports are more focused on cultural integration between partner countries than on economic scale. LnDIS is basically tested by a $10 \%$ significance level and the statistical coefficient is between $[-0.457,-0.784]$, indicating that the farther the geographical distance between the capitals of the two countries is, the more unfavorable it is for China's export of cultural products to countries along the Belt and Road. This result reflects the characteristics of cultural products as traditional goods, that is, the increase in the geographical distance of oil price changes increases the cost of trade. LnFTAdj are both significant and negative at the statistical level of $10 \%$ or $5 \%$, it is said that when China signs bilateral trade agreements or regional trade agreements with more non-partner countries, it is even more detrimental to the trade of cultural products between the two countries. This may be because China has given preferential policies to trade in more country, which has relatively worsened its trading environment for the partner countries, thus creating greater export competitiveness for partner countries. LnCDI is significant and negative at the level of $5 \%$ and $10 \%$, indicating that the bigger the cultural distance between partner countries and China, the more unfavorable China's export of cultural products of the "Belt and Road" countries. With the expansion of cultural distance, the cultural acceptance between the two countries is smaller, the cultural products export market of partner countries is narrowed.

The coefficient of lnOFDIs is positive but not significant, indicating that China's direct investment in the "Belt and Road" countries is conducive to the export of its cultural products. Due to the entry of China's OFDI, more brands and products with Chinese elements have entered the partner countries, accelerating the understanding of China by the residents of the partner countries, improving the acceptance of Chinese culture, thereby improving the export environment of cultural products of partner countries. The coefficient of $\operatorname{lnES}$ and $\operatorname{lnOPENj}$ are positive but not significant, that is, when the "Belt and Road" countries have high economic freedom or high trade openness, it is beneficial to China's export of cultural products. The reason may be higher economic freedom or trade openness makes the partner countries more open to Chinese cultural products. The statistical coefficients of lnhc and lnict are positive and tested by the $1 \%$ and $5 \%$ significance levels, respectively. It shows that increase of high-education among residents of partner countries and the increase of Internet access rate have broadened the channels for residents of partner countries to understand Chinese culture, thus facilitating the export of Chinese cultural products. 
TABLE I. FULL SAMPLE TEST

\begin{tabular}{|c|c|c|c|c|c|c|c|}
\hline & (1) & (2) & (3) & (4) & (5) & (6) & (7) \\
\hline $\begin{array}{l}\text { VARIAB } \\
\text { LES }\end{array}$ & $\operatorname{lnEcp}$ & $\operatorname{lnEcp}$ & $\operatorname{lnEcp}$ & $\operatorname{lnEcp}$ & $\operatorname{lnEcp}$ & $\operatorname{lnEcp}$ & $\operatorname{lnEcp}$ \\
\hline \multirow[t]{2}{*}{$\operatorname{lnGDPi}$} & $\begin{array}{c}0.773^{* *} \\
*\end{array}$ & $\begin{array}{c}1.031^{* *} \\
*\end{array}$ & $\begin{array}{c}1.170^{* *} \\
*\end{array}$ & $0.715^{* *}$ & $\begin{array}{c}1.112^{* *} \\
*\end{array}$ & 0.608 & $0.789^{* *}$ \\
\hline & $(0.291)$ & $(0.309)$ & $(0.391)$ & $(0.346)$ & $(0.330)$ & $(0.376)$ & $(0.319)$ \\
\hline \multirow[t]{2}{*}{$\operatorname{lnGDPj}$} & $0.678^{*}$ & 0.561 & 0.522 & $0.885^{* * *}$ & 0.434 & 0.271 & 0.194 \\
\hline & $(0.358)$ & $(0.357)$ & $(0.364)$ & $(0.431)$ & $(0.399)$ & $(0.469)$ & $(0.380)$ \\
\hline \multirow[t]{2}{*}{$\operatorname{lnDIS}$} & -0.457 & $-0.544 *$ & $-0.510^{*}$ & $-0.515^{*}$ & $-0.674 *$ & $-0.745^{* *}$ & $-0.784 * *$ \\
\hline & $(0.292)$ & $(0.290)$ & $(0.297)$ & $(0.296)$ & $(0.342)$ & $(0.331)$ & $(0.301)$ \\
\hline \multirow[t]{2}{*}{ InFTAdj } & $\begin{array}{c}- \\
0.789 * * \\
*\end{array}$ & $\begin{array}{c}- \\
0.723^{* * *} \\
*\end{array}$ & $\begin{array}{c}- \\
0.752 * * \\
*\end{array}$ & $-0.647 *$ & $\begin{array}{c}-\bar{c} \\
0.747^{* *} \\
*\end{array}$ & $-0.699 *$ & $\begin{array}{c}- \\
0.898^{* *} \\
*\end{array}$ \\
\hline & $(0.261)$ & $(0.259)$ & $(0.264)$ & $(0.340)$ & $(0.262)$ & $(0.372)$ & $(0.264)$ \\
\hline \multirow[t]{2}{*}{$\operatorname{lnCDI}$} & & $-16.04 * *$ & $-16.26^{* *}$ & $-14.75^{*}$ & $-14.98^{* *}$ & -8.744 & $-12.99^{*}$ \\
\hline & & $(7.274)$ & $(7.300)$ & $(7.462)$ & $(7.434)$ & (7.783) & (7.244) \\
\hline \multirow[t]{2}{*}{ lnOFDIs } & & & 0.0565 & & & & \\
\hline & & & $(0.0966)$ & & & & \\
\hline \multirow[t]{2}{*}{$\operatorname{lnES}$} & & & & 2.146 & & & \\
\hline & & & & $(1.351)$ & & & \\
\hline \multirow[t]{2}{*}{$\operatorname{lnOPENj}$} & & & & & 0.360 & & \\
\hline & & & & & $(0.499)$ & & \\
\hline \multirow[t]{2}{*}{$\operatorname{lnhc}$} & & & & & & $\begin{array}{c}1.407 * * \\
*\end{array}$ & \\
\hline & & & & & & $(0.402)$ & \\
\hline \multirow[t]{2}{*}{ Inict } & & & & & & & $0.539^{* * *}$ \\
\hline & & & & & & & $(0.215)$ \\
\hline \multirow[t]{2}{*}{ Constant } & $\begin{array}{c}- \\
25.90^{* *} \\
*\end{array}$ & $-23.00 * *$ & $-24.87 * *$ & $\begin{array}{c}- \\
31.52 * * \\
*\end{array}$ & $-22.79 * *$ & -14.38 & -12.35 \\
\hline & $(9.136)$ & (9.108) & $(9.671)$ & (10.38) & $(9.129)$ & $(11.36)$ & $(9.903)$ \\
\hline $\begin{array}{c}\text { Observati } \\
\text { ons }\end{array}$ & 210 & 210 & 210 & 210 & 210 & 210 & 210 \\
\hline R-squared & 0.709 & 0.721 & 0.739 & 0.697 & 0.718 & 0.724 & 0.747 \\
\hline $\begin{array}{l}\text { Number of } \\
\text { id }\end{array}$ & 30 & 30 & 30 & 30 & 30 & 30 & 30 \\
\hline
\end{tabular}

Since the "Belt and Road" countries are mostly developing countries, it is necessary to conduct sample testing in developing countries to ensure that full-sample testing is not accidental. After testing, the statistical coefficient symbol and significance of the sample test in developing countries have not changed significantly, which can prove the robustness of the full-sample test.

\section{CONCLUSIONS AND SUGGESTIONS}

\section{A. Conclusions}

Based on the panel data of China and the "Belt and Road" countries from 2009 to 2015 , this paper analyzes the influencing factors of China's export of cultural products along the "Belt and Road" countries using a fixed-effects model. The results show that China's GDP scale, the GDP scale of partner countries, the economic freedom of partner countries, the degree of education in partner countries and the degree of communication with the outside world have a significant positive impact on China's Export of Cultural Products to Countries along the Belt and Road. However, the results also show that the multilateral resistance factor, the geographical and cultural distance between the two countries have a significant negative impact on China's export of cultural products to countries along the Belt and Road. It shows that the larger the scale of China's economy and the stronger its economic strength, the more likely it is to increase the influence of Chinese culture, thus the more favorable it is to export cultural products to countries along the "Belt and Road". The country's relatively free economy, high level of education and openness to information in the "Belt and Road" countries are also beneficial to China's export of cultural products. The bigger geographical distance and cultural distance between the two countries, or China's signing of bilateral trade agreements or regional trade agreements with more non-partner countries will adversely affect the export of cultural products in countries along the "Belt and Road".

\section{B. Policy suggestion}

In recent years, China's cultural industry has developed rapidly, and the concept of "going out" of culture has been deeply rooted in the hearts of the people. Especially since the cultural self-confidence put forward by General Secretary Xi Jinping at the 19th National Congress, the export of cultural products has increasingly become the focus of attention in the future. As a new growth point of China's export trade, it is of great significance to study China's factors affecting the export of cultural products to the "Belt and Road" countries. This article gives the government and enterprises some inspirations: Firstly, we must make full use of the advantages of small cultural distance and similar culture in some countries along the "Belt and Road" to actively consolidate and expand the acceptance of Chinese cultural products in culturally similar areas, especially in the Chinese cultural circle. These countries or regions are traditional regions for the export of Chinese cultural products. While continuing to stabilize its cultural exports, we should actively rely on these regions to promote the further spread of Chinese culture. Secondly, we should deeply understand the essential characteristics of cultural products and the characteristics of consumer preferences. As far as enterprises are concerned, it is necessary to use various promotion measures to achieve access to foreign markets, and use various forms of propaganda methods such as the Internet to broaden the channels of communication of Chinese culture and play a positive role in promoting the development of cultural products. Thirdly, the construction of free trade zones and regional trade agreements will reduce exports to other countries, but as the number of free trade zones has increased, the marginal impact of new free trade zones on exports to other countries will continue to decrease. Therefore, China should continue to adhere to the trade open strategy and actively promote the construction of a free trade zone with the "Belt and Road" countries.

\section{REFERENCES}

[1] Guo R.Linguistic and Religious influences on Foreign Trade: Evidence from East Asia [J].Asian Economic Journal, 2007, 21(1):101-121.

[2] Montalvo J G, Rynal Q M.Ethnic Diversity and Economic Development [J] Journal of Development Economics, 2005, 76(2):293-323.

[3] Jaimovich, Estehan. "Import Diversification along the Growth Path, "Economics Letter, 2012, 117, pp.306-310.

[4] Hofstede U. Culture's Consequences; Comparing Values, Behaviors, institutions, and Organizations across Nations [J]. Behaviour Research and Therapy, 2003, 41(7):861-862.

[5] Jeffrey H. Bergstrand," The Gravity Equation in International Trade: Some Microeconomic Foundations and Empirical Evidence", the Review of Economics and Statistics, Vol. 67, No. 3 (Aug., 1985), pp. 474-481.

[6] Jeffrey H. Bergstrand," The Generalized Gravity Equation, Monopolistic Competition, and the Factor-Proportions Theory in International Trade" The Review of Economics and Statistics, Vol. 71, No. 1 (Feb., 1989), pp. 143-153.

[7] Anderson. J. E. and E. V. "Gravity with A Solution to the Puzzle." American Economic, 2003, 93(1), pp. 170-192. 